\title{
The Experience of Saudi Students with Online Learning in U.S. Universities
}

\author{
May Alashwal \\ Department of Learning Sciences and Educational Research, University of Central Florida, Orlando, USA
}

Email address:

msalashwal@knights.ucf.edu

\section{To cite this article:}

May Alashwal. The Experience of Saudi Students with Online Learning in U.S. Universities. Higher Education Research. Vol. 5, No. 1, 2020, pp. 31-36. doi: 10.11648/j.her.20200501.16

Received: January 1, 2020; Accepted: February 4, 2020; Published: February 10, 2020

\begin{abstract}
Many significant developments have been continually and drastically evolved due to the change in the technological landscape. The consequence of technological advancements in education is the most essential and apparent among universities. The introduction of online courses has hence revolutionised the education experience for students in rendering flexibility and opportunities for learning. The present study is thereby conducted to explore and highlight the extent to which online courses and online learning, in general, expose the Saudi students in U.S. universities to new academic practices and cultural norms. For elucidating this researcher, the researcher adopted a qualitative for understanding and exploring the phenomenon. The data for the current study was collected using semi-structured interviews. To provide an overview, significant statements were analyzed and meaning units were generated for developing a full description of the phenomenon. Majorly, the participants in this study were graduate and undergraduate Saudi students who took online courses at U.S. universities between August 2015 and May 2017. The results of this study show that Saudi students' academic performance was not affected by the method of delivering courses (face-to-face vs. online). In addition, Saudi students were introduced to a new classroom culture through the online courses. The results also revealed some advantages of online courses to those students such as flexibility and convenience. Technical issues were identified as a major challenge with online course. Primarily, the results of the phenomenological study are presented to help understand how Saudi students perceive online learning in U.S. universities and inform further research and practice on how to accommodate this growing group of international students in U.S. universities.
\end{abstract}

Keywords: Saudi Student, Online Learning, Phenomenological Study, Higher Education, International Students, Western Universities

\section{Introduction}

In 2005, the late King Abdullah bin Abdulaziz (King of Saudi Arabia) introduced a scholarship program for Saudi students to study in the United States. This program was majorly introduced with the objective of building qualified Saudi individuals and further exchanging academic and cultural expertise with other countries [1]. The central objective behind the King Abdullah Scholarship Program (KASP) is to provide students with the knowledge and skills that they need to become successful. Moreover, this is aimed not only for the students but also to benefit the country. Out of the overall students who are enrolled in U.S colleges and universities, international students comprised of 24 percent as per the survey conducted and studied by the Institution of
International Education ( $\mathrm{N}=165)$. Through the study, it was also manifested that Saudi Arabia is ranked as the fourth leading place of origin for students who are getting enrolled to study in the United States [2]. Additionally, online learning is becoming a big part of U.S. higher education institutions [3]. Consequently, the major question that needs to be explored and addressed is how online learning is affecting students in general, especially international students. Saudi students who are sponsored by the Saudi government through the King Abdullah Scholarship Program are not allowed to take more than two online courses during their program of study. There is a hesitation at the Saudi Ministry of Education end in accepting any online degree from foreign institutions or accrediting any online courses taken as a part of a degree [4]. Chiefly, this hesitation comes from the fear of plagiarism 
or the fairness of students' performance in the adoption of such online courses [5]. Also, it has been discerned from one of the assistant attachés at the Saudi Arabian Cultural Mission in the U.S. that taking online courses could hinder Saudi students from being exposed to the new academic and cultural environment [6].

Nonetheless, it is crucial to shed light on the perceptions of Saudi students to understand their perspective and experience their views on online learning in U.S. universities. Consequently, this study will help in elucidating the advantages, challenges and obstacles pertaining to online learning. Therefore, the researcher aims and hopes that this study highlights how and to what extent a Saudi student is exposed to a different academic and cultural experience through online education.

\subsection{Online Education in the United States}

According to a study manifested in Ref. [7], online education is determined as a method wherein all forms of teaching and learning completely takes place via the Internet (p. 144). It has been perceived that over the decades, there has been an explosive growth in the demands and interests for online education. As a result, the necessity of developing online programs have also become more common. In 2011, more than $67 \%$ of the public higher education institutions in the U.S. who were offering online education programs considered maintaining these programs with strategic plans [3]. In a study contemplated in Ref. [8], it was stated that there are both positive and negative outcomes of online education. Besides this, it was argued that these mixed results contemplate that the quality of online education depends entirely on "how the online course is designed and taught". In Ref. [9], their synthesis of best practices in online education listed what they have discerned as best practices in the literature pertaining to the online education from accreditation to learning theories [8]. In a research intended in Ref. [10], the study was conducted to identify what determines an effective pedagogical practices of online teaching from the perspective of experienced award-winning faculty. Conclusively, their findings were consistent with what of Ref. [11] (as cited in Ref. [9]) had stated, and they were as follows:

a) Setting clear goals and expectations for the students;

b) Using different representations of the content;

c) Enabling active learning;

d) Providing frequent feedback;

e) Providing flexible choices to achieve the objectives; and

f) Providing guidance and support.

\subsection{The Development of Saudi Higher Education}

According to a report published by the Saudi Arabian Ministry of Education in Ref. [12] "The current status of higher education in the Kingdom of Saudi Arabia", the first college to be established in the country was in the year 1949 . Until the year 2000, Saudi citizens only had access to higher education through seven public universities around the
Kingdom of Saudi Arabia. However, in the last few years, the number of universities and colleges has increased to 38 public universities and 30 private universities and colleges all around the Kingdom. Both the male and female students are awarded in these universities and colleges for undergraduate, graduate, and fellowship degrees. As per the latest statistics published on higher education, the number of students currently enrolled in the year 2016 is perceived to be $1,622,441$ students [13]. In addition to providing access to higher education in the Kingdom, the King Abdullah Scholarship Program for studying abroad was initiated in 2005 with the goal to build qualified Saudi individuals and exchanging academic and cultural expertise with other countries $[14,15]$. While according to the Ministry statistics, over 174,000 students "in ESL programs and college degree programs" undertook an advantage of the scholarship program and the vast majority of them choose to study in the United States as their preferred destination [12]. As a result, the fastest-growing international student population in the United States is Saudis. However, despite that, there is very minimal research that has been done addressing some of the issues Saudi students face while adjusting to the academic and social life in the United States [16].

\subsection{Online Education in Saudi Arabia}

In Saudi Arabia, the higher education system is considered to be a traditional system. However, with the advancements in the education due to the technologies, there seems to be a gradual transformation of the traditional education of Saudi into being a blended system [17]. Subsequently, the Saudi Ministry of Education took some steps in the effort of improving the quality of higher education pertaining to the content and delivery. The rapid and advent advancements of the Information and Communication Technology infrastructure has led to the revolutionization of the education system. Thereby, it has rendered several benefits to both the students and educators. This inclusion of technology in the delivery of academic coursework, including an expanding utilization of the Internet, has enabled the universities in Saudi to extend a convenient and appropriate method for course delivery [18-21]. For instance, in 2007, the Ministry of Education responded by establishing the National Centre for E-learning and Distance Learning (NCEL) [1]. The primary goal of this center is to spread and facilitate the integration of advanced technology in higher education institutions. It also supports research in the field and provides consultation for universities and colleges regarding technology integration and online education [22]. Also, the Ministry of Education encourages universities to integrate web-based tools and technology in teaching and learning by founding deanships within each public university for elearning and distance education. These deanships conduct workshops and seminars for faculty members to educate them about the advantages of using these technologies in teaching and learning and how to effectively integrate technology to enhance the students' access and interaction with the online course content [23]. Consequently, the NCEL 
has established The Saudi Centre for Support and Counselling (SANEED) to provide educational and academic support, recommendations and assistance to all beneficiaries of e-learning [1]. Lastly, yet importantly, it is worth mentioning that online courses and blended courses are not available at all Saudi universities and are thus limited to specific disciplines [17].

\subsection{Saudi Students Characteristics}

Three decades ago, the social environment of the Saudi culture imposed specific type of norms and beliefs towards education and educators. Students coming from those generations in the Saudi education system were adapted to the notion that professors and teachers were always assumed to be right. Therefore, questioning the professor's knowledge and opinions was considered to be disrespectful and also a sign of ignorance [5]. Unlike the education system in Saudi Arabia, which is more of a teacher-centered approach that relies heavily on textbooks and lecturing, the U.S. education system is more of a learner-centered approach that relies on presentations, discussions, and collaborative learning. Consequently, Saudi students who are studying in U.S. universities used to struggle with the American classroom culture [24]. However, having the experience to study abroad, Saudi students are exposed to unique and fresh ways of learning and thinking. They are further introduced to new modes of learning such as hybrid and online learning, even new instructional strategies and activities within their faceto-face classes such as group discussions, problem-solving, and critical thinking [25].

Primarily, one of the critical characteristics of the Saudi education system is that it is a gender-segregated system. This fact can be considered as one of the most academic and social challenges which the Saudi students face when transitioning to U.S. and western universities since these systems are the opposite of what most of the Saudi students are familiar with [26]. Chiefly, the student has to undergo a shift from a traditional Islamic based education to a western-oriented education. As with all other individuals coming from different cultures, Saudis desire to maintain their affiliation with their roots but also acknowledge the importance of being engaged in the hosting culture in order to be academically successful. Cultural identity plays a vital role in the experience of these Saudi students in a mixedgender environment [27]. However, it could result in a source of conflict for these individuals, which could subsequently affect their academic success. Language is another academic challenge which is faced by the international students [28, 29] and Saudi students are no exception to that [24]. Prior research study has shown that the level of English proficiency for female Saudi students correlates positively with how fast they adjust to the new culture [16]. Moreover, some of the Saudi students, especially females, feel isolated because they are shy or do not know how to interact with people from the hosting culture and also afraid of making grammar mistakes when talking to the natives [24]. Higher education institutions in the Western world need to understand the international students' learning preferences, backgrounds, and past experiences in teaching and learning, especially online learning, in this case, to help international students to adapt to this new classroom culture [29]. Besides this, designing an online course that accounts for the cultural differences among international students can enrich the learning experience and promote full participation [28].

Conclusively, there is a lack of research on the experience of Saudi students with online learning in U.S. universities. Giving the fact that Saudi students are the fastest-growing international student population in the U.S., it is very crucial to explore and highlight such topic and find possible implications to help instructors, instructional designers, and institutions accommodate these students' needs. In the present study, the researcher aims to understand how online learning affects Saudi students' social engagement and academic performance. Subsequently, the researcher further aims to uncover and manifest study on what cultural differences instructional designers and instructors should be aware of when designing and delivering an online course for Saudi students. Furthermore, this study delves into the role of online learning in preparing Saudi students to transition to western classroom culture.

\section{Methodology}

In order to address the gap in the literature, the researcher aims to present a phenomenological qualitative study that explores the experience of Saudi students taking online courses at Southeastern universities in the United States. According to a study manifested in Ref. [30], phenomenology is determined as the study of the reality from the individuals who are associated with this reality or phenomena. In other words, the goal of phenomenology is to understand the lived experience of individuals. For understanding what kind of academic or cultural experience the Saudi students had with online courses and how these courses influenced their academic achievement, the researcher has intended to choose this phenomenological methodology of research.

\subsection{Population and Sampling}

The data was primarily collected using semi-structured interview questions from four chosen participants (three were one-on-one interviews, and one was conducted via the email) who were selected based on some criteria and were thereby invited to participate in the study. Moreover, a purposeful maximum variation sampling method was employed in the current study to capture the common patterns among variations. The researcher sought to find participants, Saudi students' males and females who have taken at least one online course during their program degrees, graduate and undergraduate, which were the criteria that were used to invite the participants. Only female participants were found and agreed to be a part of this study. All the male students that the researcher approached did not take any online 
courses. This could be a result of the limitations imposed on Saudi students by the scholarship program regarding taking online courses. Four females were interviewed, three of them were graduate students, while one was an undergraduate student.

\subsection{Data Collection}

Before collecting any data, Institutional Review Board (IRB) approval was needed. A semi-structured interview approach was used for collecting data to allow for obtaining additional information when possible. The participants were interviewed by the researcher individually to talk about their experiences. In addition to this, the interviews were audiorecorded, and notes were written subsequently while conducting the session of the interview. However, for the interview conducted via mail, no such audio recording was done. A report was prepared at the end after conducting the interview to document the responses obtained during the interview. The researcher subsequently sent the gathered responses to the respondents in order to ensure the accuracy of the information discussed during the interviews. This strategy enabled the respondents to further give them a chance to add any information they might have missed during the interviews. Upon completion of the participants interviewing process, all the reports were reviewed and prepared thoroughly for the data analysis. The most integral part of this procedure was that the researcher did not disclose the identity of the participants and hence used pseudonyms in the reports.

\subsection{Data Analysis}

After conducting interviews with the four respondents individually, the researcher transcribed each one of the interview word by word to read through it and look for emerging themes. The data were analyzed using a process of coding and categorizing. Initially, the significant statements or sentences were highlighted by the researcher that rendered an understanding of the participant's experience with online learning. Subsequently, these significant statements were grouped into clusters of meaning to develop the major themes. Later, the refined themes were used to write a full description of the participants' experience [31].

\section{Results and Discussion}

Upon analyzing the data, certain themes and contradictions emerged, that will be discussed later. However, the data also asserted that online learning does not necessarily have any significant effect on the Saudi students' performance, and they still succeeded in achieving good grades (i.e. A and B grades) in the online courses as well as in face-to-face courses. However, they did not believe that online courses had introduced them to western culture as face-to-face courses would. It is through the current study only that the researcher discerned that online courses have come up with a new way of teaching and learning.

\subsection{Online Courses had no Negative Effect on Academic Performance}

All four participants agreed on the fact that their academic performance was not at all affected by the method of delivering the course (online vs. face-to-face). Despite the fact that online courses demand more effort somehow, as they explained, they still achieved high grades, as did they in face-to-face courses.

\subsection{Online Courses have not Introduced the Saudi Students to Western Culture, But to a New Classroom Culture}

There was a consensus to some degree that online courses did not expose the four participants to western culture in everyday life. In response to this, one of the respondents cited and explained this during the interview that, "Since the cultures are more distinct to the face-to-face classes". However, as per the view of the other participant, online courses have introduced her to a new classroom culture. From her perspective, online courses introduced her to new and innovative world of teaching and learning, wherein the technology allows for a more convenient way to learn and "how to make it easier for some people to get an education, and give them more opportunities to accomplish their goals and reach their dreams."

\subsection{Online Course Is the Absolute Preference Because of the Flexibility and Convenience that It Offers}

All four participants agreed upon the flexibility and the convenience that online courses offer. The fact that online course gives the students the ability to choose when and where to study was of significant advantages, especially for the participants who have other commitments like family in their lives, one of the participants stated "It was a great option for me because I already have a commitment with my family".

\subsection{Technical Issues Are the Major Challenge in Online Courses}

The failure of the technology and the Internet was a critical theme when it comes to the challenges the participants had faced with online courses, one participant explained "Technology can fail you; you need to have a very good Internet connection in order to listen to online lectures". For two of the participants, the response time for the instructors was considered as a challenge for them, "some instructors take too long to respond or don't respond at all".

\subsection{Plagiarism}

For some participants, they did not think of plagiarism as a problem in online courses. However, one of the participants pointed out that the instructors use online tools (TurnitIn) to ensure that the students are not cheating. However, one of the respondents also had a notion that cheating could be a problem in online courses saying, "There is room for 
plagiarism in online courses because you cannot know if the student completed the work her/himself or if the students got a help completing a quiz".

\section{Conclusion}

The present study seeks to identify the experience of Saudi students taking online courses at U.S. universities in order to get a better understanding of the advantages, challenges, and obstacles, which Saudi students have with online learning. Also, this study further attempts to answer, to some degree, how and to what extent a Saudi student is exposed to a different academic and cultural experience through online courses. Transitioning students into a different learning culture and environment can be challenging. Conclusively, the findings from the current research study can assist U.S. institutions to understand the challenges that a Saudi student faces upon coming to the American classroom and thereby help to facilitate the transition for these students. It has been perceived that online learning has excellent potentials such as providing access to education for more diverse groups and the flexibility in terms of access to education and completion in their own pace for students who have other commitments in their lives. The student-centered environment found in the online courses exposed the students to new ways of learning, such as active learning and collaborative learning. Moreover, online courses are convenient especially to the students who have family commitments. The fact that some of the Saudi students studying in the U.S. have their family with them makes this unique style of education through online courses a great option for them. However, due to some restrictions posed by the sponsoring party of the Saudi Scholarship Program, Saudi students are not allowed to take more than two online courses during their tenure. As indicated before, these restrictions come from the fears that online courses do not expose the students to new academic experience or cultural norms. Yet, the findings from the current study clearly assert that Saudi students have experienced some unique aspects of classroom culture through online courses. Future research may focus on exploring the differences if any between male and female Saudi students in regard to their experience with online courses in U.S. universities.

\section{Appendix}

\section{Interview Protocol}

Icebreaking questions

a) Describe your experience with taking courses at (the American university).

How is it different from the courses you took in Saudi universities "if you studied there"?

b) What about your major? How many courses you should take? How many you took already? The nature of the courses you took so far (online vs. f2f).

\section{Main Questions}

a) Describe the nature of the online courses you took.

1) Survey course vs. specialized course.

2) What was the coursework?

3) The assignments and the activities?

b) Thinking of one of the online courses you took, compare it with a traditional face-to-face course. How do they differ in terms of easiness, workload and motivation to participate?

1) How about the interactions between you and the instructor and you and your colleagues?

2) What are some of the advantages of the online courses?

3) Tell me about your positive experience with online courses.

4) Tell me about the challenges you faced (if any) with online courses.

c) Some would say that there is some room for plagiarism in an online course. What would you say about that? Did you have any direct or indirect experience with such situation? Do you care to explain?

d) Do you prefer taking an online course or face-to-face course? And why would you choose one over the other?

\section{References}

[1] M. Alamri, "Higher education in Saudi Arabia," Journal of Higher Education Theory and Practice, vol. 11, no. 4, pp. 88-91, 2011.

[2] C. Farrugia and N. Andrejko, "Shifting tides? Understanding international student yield for fall 2017," IIE Center for Academic Mobility Research and Impact. Institute of International Education, 2017.

[3] I. E. Allen and J. Seaman, Going the distance: Online education in the United States, 2011. ERIC, 2011.

[4] H. S. Al-Khalifa, "The state of distance education in Saudi Arabia," ELearn, vol. 2009, no. 10, p. 9, 2009.

[5] A. K. Hamdan, "The reciprocal and correlative relationship between learning culture and online education: A case from Saudi Arabia," The International Review of Research in Open and Distributed Learning, vol. 15, no. 1, 2014.

[6] K. Fischer, "Foreign students aren't edging out locals, numbers show," The Chronicle of Higher Education, 2015.

[7] A. G. Picciano, "Planning for online education: A systems model," Online Learning, vol. 19, no. 5, pp. 142-158, 2015.

[8] S. S. Jaggars and D. Xu, "How do online course design features influence student performance?" Computers \& Education, vol. 95, pp. 270-284, 2016.

[9] C. J. Grandzol, "Best practices for online business education," The International Review of Research in Open and Distributed Learning, vol. 7, no. 1, 2006.

[10] C. J. Bailey and K. A. Card, "Effective pedagogical practices for online teaching: Perception of experienced instructors," The Internet and Higher Education, vol. 12, no. 3-4, pp. 152$155,2009$. 
[11] A. W. Chickering and Z. F. Gamson, "Seven principles for good practice in undergraduate education," AAHE bulletin, vol. 3 , p. 7,1987

[12] O. Alrashidi and H. Phan, "Education Context and English Teaching and Learning in the Kingdom of Saudi Arabia: An Overview," English Language Teaching, vol. 8, no. 5, pp. 33$44,2015$.

[13] A. Alsubaie and K. Jones, "An overview of the current state of women's leadership in higher education in Saudi Arabia and a proposal for future research directions," Administrative Sciences, vol. 7, no. 4, p. 36, 2017.

[14] L. Smith and A. Abouammoh, "Higher education in Saudi Arabia: Reforms, challenges and priorities," in Higher Education in Saudi Arabia: Springer, 2013, pp. 1-12.

[15] A. A. Tayeb and D. C. Hoy, Evaluation of the Center for Teaching and Learning Development in King Abdulaziz University Jeddah Compared to Selected Other Centers. University of Manchester, 2003.

[16] E. M. Lefdahl-Davis and K. M. Perrone-McGovern, "The cultural adjustment of Saudi women international students: A qualitative examination," Journal of Cross-Cultural Psychology, vol. 46, no. 3, pp. 406-434, 2015.

[17] U. T. Alturki, "The development of online distance education in Saudi Arabia," eLearn, vol. 2014, no. 11, 2014.

[18] A. A. Al Saif, The motivating and inhibiting factors affecting the use of web-based instruction at the University of Qassim in Saudi Arabia. Wayne State University, 2005.

[19] S. Alkhalaf, J. Nguyen, A. Nguyen, and S. Drew, "The potential role of collaborative learning in enhancing e-learning systems: Evidence from Saudi Arabia," Australian Society for Computers in Learning in Tertiary Education, 2011.

[20] I. Alzahrani and J. Woollard, "The Potential of Wiki Technology as an E-Learning Tool in Science and Education; Perspectives of Undergraduate Students in Al-Baha University, Saudi Arabia," Online Submission, 2012.

[21] N. M. Alotaibi and A. Tayeb, "The Extent of Practicing the Skills of Team Work Leadership among Heads of Departments in Directorate of Education in Methnb, Saudi Arabia: A Field Study," Journal of Education and Practice, vol. 7, no. 30, pp. 104-113, 2016.

[22] T. M. N. Khawaji, "Web 2.0 technology: Social learning tools in higher education in Saudi Arabia," 2016.

[23] S. Alkhalaf, J. Nguyen, A. Nguyen, and S. Drew, "Online learner satisfaction and collaborative learning: Evidence from Saudi Arabia," International Journal of Information and Communication Technology Education (IJICTE), vol. 9, no. 2, pp. 66-78, 2013.

[24] D. Al Remaih, Social and academic challenges facing Saudi female students in the United States of America. The Claremont Graduate University, 2016.

[25] R. Alebaikan and S. Troudi, "Blended learning in Saudi universities: challenges and perspectives," ALT-J, vol. 18, no. 1, pp. 49-59, 2010.

[26] A. Alhazmi and B. Nyland, "The Saudi Arabian international student experience: From a gender-segregated society to studying in a mixed-gender environment," Compare: A Journal of Comparative and International Education, vol. 43, no. 3, pp. 346-365, 2013.

[27] S. Alanazy, "Saudi students' attitudes, beliefs, and preferences toward coeducational online cooperative learning," 2011.

[28] X. Liu, S. Liu, S. Lee, and R. J. Magjuka, "Cultural differences in online learning: International student perceptions," Educational Technology \& Society, vol. 13, no. 3, pp. 177-188, 2010.

[29] E. Sawir, "Language difficulties of international students in Australia: The effects of prior learning experience," International Education Journal, vol. 6, no. 5, pp. 567-580, 2005.

[30] G. M. D. B. W. R. G. Jp, "Educational research: An introduction 8th ed Allyn and Bacon White Plains," ed: NY, 2006.

[31] J. W. Creswell, "Qualitative Inquiry \& Research Design Choosing Among Five Approaches. Sage Publications," Thousand Oaks, CA, 2007. 